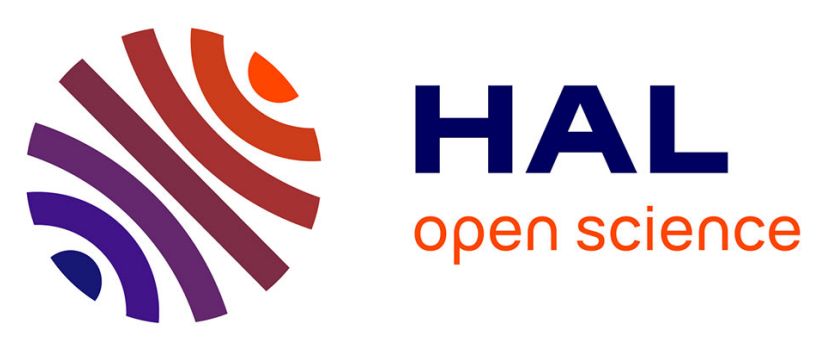

\title{
An assessment of the QUB/e method for fast in situ measurements of the thermal performance of building fabrics in cold climates
}

Johann Meulemans

\section{- To cite this version: \\ Johann Meulemans. An assessment of the QUB/e method for fast in situ measurements of the thermal performance of building fabrics in cold climates. Cold Climate HVAC 2018 - The 9th International Cold Climate Conference, Lund University, Mar 2018, Kiruna, Sweden. hal-01737563}

\author{
HAL Id: hal-01737563 \\ https://hal.science/hal-01737563
}

Submitted on 19 Mar 2018

HAL is a multi-disciplinary open access archive for the deposit and dissemination of scientific research documents, whether they are published or not. The documents may come from teaching and research institutions in France or abroad, or from public or private research centers.
L'archive ouverte pluridisciplinaire HAL, est destinée au dépôt et à la diffusion de documents scientifiques de niveau recherche, publiés ou non, émanant des établissements d'enseignement et de recherche français ou étrangers, des laboratoires publics ou privés. 


\title{
An assessment of the QUB/e method for fast in situ measurements of the thermal performance of building fabrics in cold climates
}

\author{
Johann Meulemans*1 \\ ${ }^{1}$ Saint-Gobain Recherche, Aubervilliers, France
}

\begin{abstract}
The QUB/e method is a dynamic measurement method developed to estimate the whole heat loss coefficient and local $U$-values of a building in a single night without occupancy. The ability of the method to provide reliable results was demonstrated experimentally in a climate chamber with controlled conditions in a previous work.

This paper presents the findings from a series of in situ measurements carried out in a circa 1960s multi-family housing located in Stockholm area (Sweden). The $U$-values estimated with the QUB/e method were in good agreement with the quasi steady-state (ISO 9869-1) values (i.e., the relative differences were within the uncertainty bound of the measurement methods). It was thus demonstrated that the QUB/e method can deliver a good estimation of the thermal performance of building fabrics within just one night, significantly less than the 2-4 week period required for quasi steady-state methods.
\end{abstract}

Keywords: Heat loss coefficient, $U$-values, QUB/e method, ISO 9869-1

\section{Introduction}

The performance gap between the design and the as-built thermal performance of buildings is an issue of high importance for the construction industry and reducing this gap has been the subject of significant research (e.g., see [1-3] and references therein). Assessing the design thermal performance is straightforward; however estimating the as-built performance of a building presents several technical challenges that often restrict its wider implementation. One of the most common challenges is the time required to perform such testing [4].

The whole Heat Loss Coefficient (HLC, in $\mathrm{W} \mathrm{K}^{-1}$ ) of a dwelling is the total power needed to maintain a constant interior/exterior temperature difference at steady-state (i.e., the inverse of a thermal resistance). The whole HLC is thus the aggregate of transmission heat losses (including thermal bridges) and infiltration heat losses; it characterizes the thermal performance of the building fabric. It should be noted that its value may be prone to variations due to the influence of the exterior environment (e.g., wind) on either the transmission losses or the infiltration losses.

The QUB/e method is a dynamic measurement method developed to estimate the whole HLC and local $U$-values of a building in a single night without occupancy [5,6]. This makes it suitable for large scale use by industry to test the actual performance of buildings. The

*johann.meulemans@saint-gobain.com 
ability of the method to provide reliable results was demonstrated experimentally in a climate chamber with controlled conditions for both the whole HLC and local $U$-values [5, 6] and in a real climate for the whole HLC only [7-9].

In this study, a comprehensive set of in situ measurements were performed in a circa 1960s multi-family housing (MFH) located in Årsta (Stockholm area, Sweden) to (i) evaluate the thermal performance of the building fabric (i.e., whole HLC and local $U$-values) before a full retrofit programme, and (ii) validate, in a real climate, the QUB/e method by crosscomparison with quasi steady-state measurements.

This paper is organised as follows. The materials and methods used in this study are described in Section 2. The results obtained from in situ measurements are presented and discussed in Section 3. Concluding remarks can be found in Section 4.

\section{Materials and methods}

\subsection{Description of the building}

The measurements took place in an apartment on the $11^{\text {th }}$ floor of a circa 1960s multi-family housing (MFH) located in Årsta (Stockholm area, Sweden). A view of the building and the layout of the apartment are shown in Figure 1.

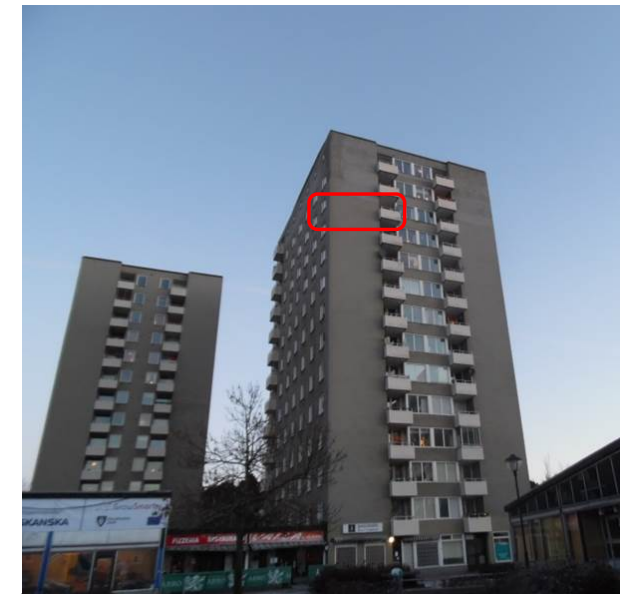

(a) View of the external façade. The red rectangle corresponds to the location of the apartment.

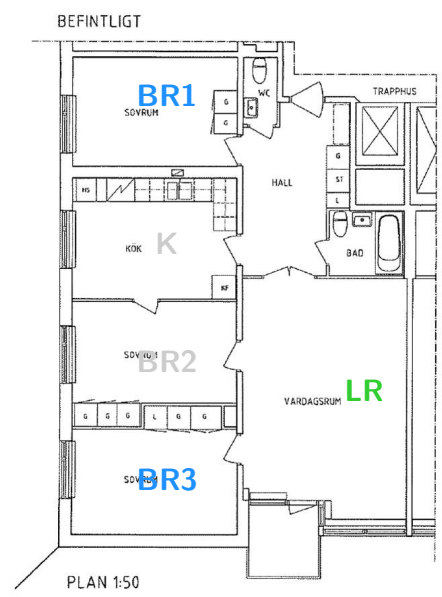

(b) Layout ( $\mathrm{BR}=$ bedroom, $\mathrm{K}=$ kitchen, $\mathrm{LR}=$ living room)

Figure 1: Overview of the apartment

The wall construction is aerated concrete and the windows are double glazing units (DGU) with wood frames. The apartment has South - West orientation, floor area, attached area and net heated area of approximately $90 \mathrm{~m}^{2}, 224 \mathrm{~m}^{2}$ and $269 \mathrm{~m}^{2}$, respectively. It should be noted that the window-to-external wall ratio is quite high (i.e., 35\%) and the proportion of the net heated area in contact with the exterior is low (i.e., $45 \mathrm{~m}^{2}$ or $17 \%$ of the total net heated area) but typical for an apartment in a MFH.

\subsection{HeatFlowMeter (HFM) method (ISO 9869-1)}

The heat flowmeter method (HFM) [10] is a quasi-static approach used to estimate the thermal transmission properties of plane building components, primarily consisting of opaque layers perpendicular to the heat flow and having no significant lateral heat flow (i.e., relatively far from thermal bridges). The appropriate location(s) may be investigated by infrared 
thermography (in accordance with standard EN 13187 [11]). The heat flux and the temperatures are monitored and the thermal transmittance $U$ (in $\mathrm{W} \mathrm{m}^{-2} \mathrm{~K}^{-1}$ ) can be computed with the following formula (average method):

$$
U=\frac{\sum_{j=1}^{n} q_{j}}{\sum_{j=1}^{n}\left(T_{i n t, j}-T_{e x t, j}\right)}
$$

where $q_{j}, T_{i n t, j}$ and $T_{e x t, j}$ are, respectively, the heat flux density $\left(\mathrm{W} \mathrm{m}^{-2}\right)$, the interior environmental (ambient) temperature $(\mathrm{K})$ and the exterior environmental (ambient) temperature $(\mathrm{K})$ of the $\mathrm{j}^{\text {th }}$ individual measurement. The duration of the test should exceed $72 \mathrm{~h}$ (normative). Usually, the thermal transmission properties can be determined after a couple of weeks for a building in the field. The total uncertainty of the measurements is expected to be between $14 \%$ and $28 \%$ if the standard ISO $9869-1$ is followed carefully [10].

The HFM (ISO 9869-1) can be performed during a co-heating test [12, 13], the whole heat loss coefficient and local $U$-values can be thus determined simultaneously (e.g., [14]). A better accuracy of the in situ $U$-values can be obtained thanks to a stable elevated temperature during heat flux measurement period.

The evolution of air temperatures and heat flux densities passing through a glazing and an external wall during an ISO 9869-1 measurement period in Årsta (Sweden) is illustrated on Figure 2.

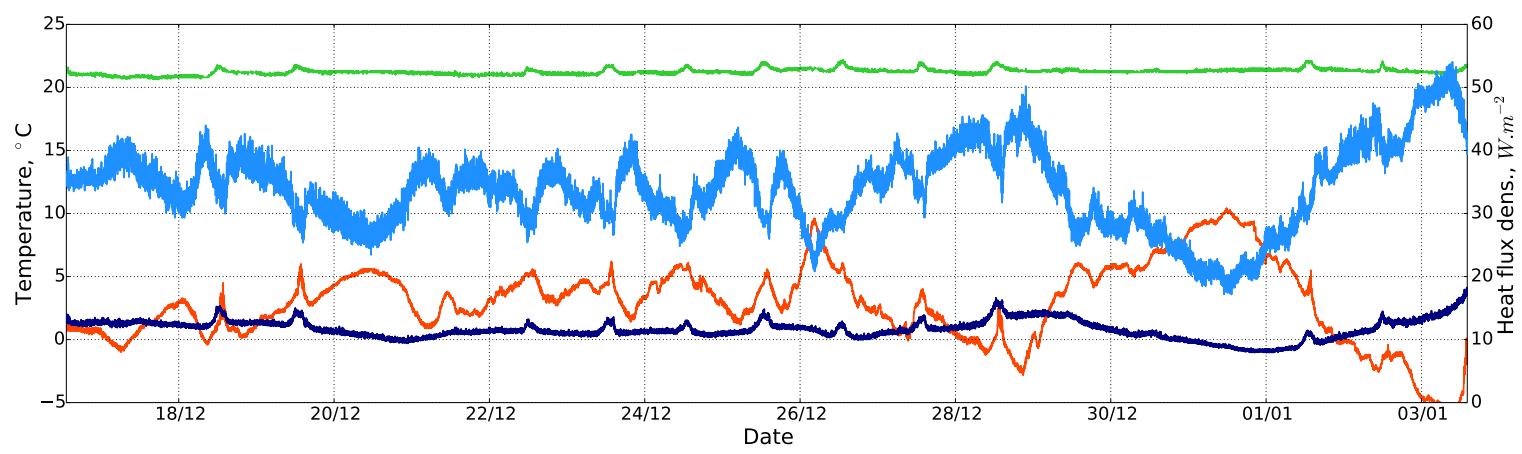

Figure 2: Evolution of air temperatures (green solid line $=$ internal air temperature, red solid line $=$ external air temperature) and heat flux densities (light blue solid line = glazing, navy blue solid line = external wall) during an ISO 9869-1 measurement period in Årsta (Sweden)

\subsection{QUB/e method}

The QUB method $[7-9,15-17]$ is a dynamic method developed to determine the as-built whole HLC of dwellings within one night without occupancy. The test commences after sunset and finishes before sunrise of the following day (see Figure 3). The principle of the QUB method is based on a single resistance and capacity model where the building is represented by a global thermal resistance $R$ (the reciprocal of HLC of the building) and a global capacitance, $C$ (the internal heat capacity). Internal and external temperature nodes ( $T_{\text {int }}$ and $T_{\text {ext }}$ respectively) are considered homogeneous and heat exchange between the two nodes occurs through the thermal resistance, $R$. Therefore, the energy input, $P(t)$, is heat lost through the envelope and stored/released by the thermal mass of the fabric (see Equation 2).

$$
P=\frac{T_{i n t}-T_{e x t}}{R}+C \frac{d T_{i n t}}{d t}
$$




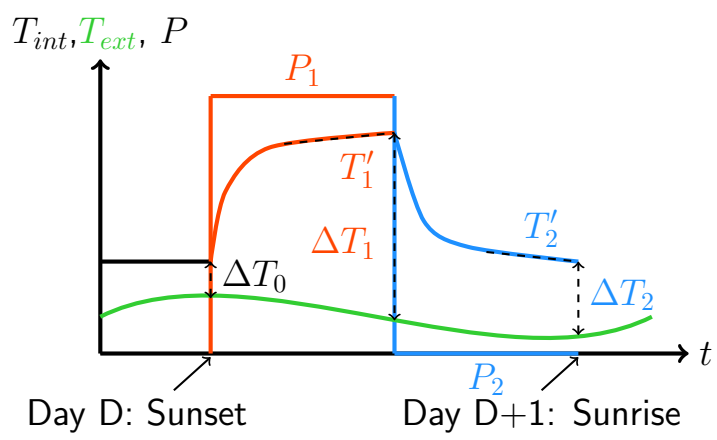

Figure 3: Evolution of temperature and power during a QUB test

The two unknowns, $R$ and $C$ in Equation 2, can be determined by using two different constant powers in two different phases (respectively noted 1 and 2 in Figure 3). The HLC can then be determined by the following formula:

$$
H L C=\frac{T_{2}^{\prime} P_{1}-T_{1}^{\prime} P_{2}}{T_{2}^{\prime} \Delta T_{1}-T_{1}^{\prime} \Delta T_{2}}
$$

where $P_{i}$ is the power input during phase $i, T_{i}^{\prime}$ is the slope of the temperature profile at the 'end' of phase $i$ (i.e., for $t \in\left[t_{i_{0}}+d_{i}-\min \left(d_{i} / 2, \tau\right), t_{i_{0}}+d_{i}\right]$ where $t_{i_{0}}$ is the beginning of phase $i, d_{i}$ the duration of phase $i$ and $\left.\tau=4 \mathrm{~h}\right)$ and $\Delta T_{i}$ is the internal to external temperature difference at the end of phase $i$. For increased accuracy it is aimed that the test is carried in an empty unoccupied dwelling without additional heat sources and in most cases there is almost no power input in phase $2\left(P_{2} \approx 0 \mathrm{~W}\right)$, i.e. this is the free cooling phase).

The error on the estimated HLC with the QUB method depends on a dimensionless parameter $\alpha[5,6,8,9,17]$ defined as follows:

$$
\alpha=1-\frac{H L C_{r e f} \Delta T_{0}}{P_{1}}
$$

where $H L C_{r e f}, P_{1}$ and $\Delta T_{0}$ are a reference heat loss coefficient (theoretical or determined experimentally, in $\mathrm{W} \mathrm{K}^{-1}$ ), the heating power (in $\mathrm{W}$ ) and the initial temperature difference (in $\mathrm{K}$ ) between the internal and external environment (i.e., at the beginning of a QUB test), respectively. The QUB method is able to provide reasonably consistent results (i.e., with a coefficient of variation of $\pm 10 \%$ ) provided the dimensionless parameter $\alpha$ lies within the recommended range (i.e., between 0.4 and 0.7 ) $[5,6,8,9,17]$.

With the QUB/e method [5, 6], heat flux densities and nearby air temperatures for each building element of interest are monitored during a QUB test. The QUB analysis procedure is then used to derive the $U$-values of each building element:

$$
U=\frac{T_{2}^{\prime} q_{1}-T_{1}^{\prime} q_{2}}{T_{2}^{\prime} \Delta T_{1}-T_{1}^{\prime} \Delta T_{2}}
$$

where $q_{i}, T_{i}^{\prime}$ and $\Delta T_{i}$ are, respectively, the mean heat flux density, the slope of the inside air temperature and the inside/outside air temperature difference at the 'end' of the phase $i$ (i.e., for $t \in\left[t_{i_{0}}+d_{i}-\min \left(d_{i} / 2, \tau\right), t_{i_{0}}+d_{i}\right]$ where $t_{i_{0}}$ is the beginning of phase $i, d_{i}$ the duration of phase $i$ and $\tau=4 \mathrm{~h})$.

The Taylor series method for uncertainty propagation [18] is used to compute the relative uncertainty associated to the HLC and the $U$-values.

The evolution of the heating power, the air temperatures and the heat flux passing through a building element during a QUB/e test in Årsta (Sweden) is illustrated on Figure 4. 

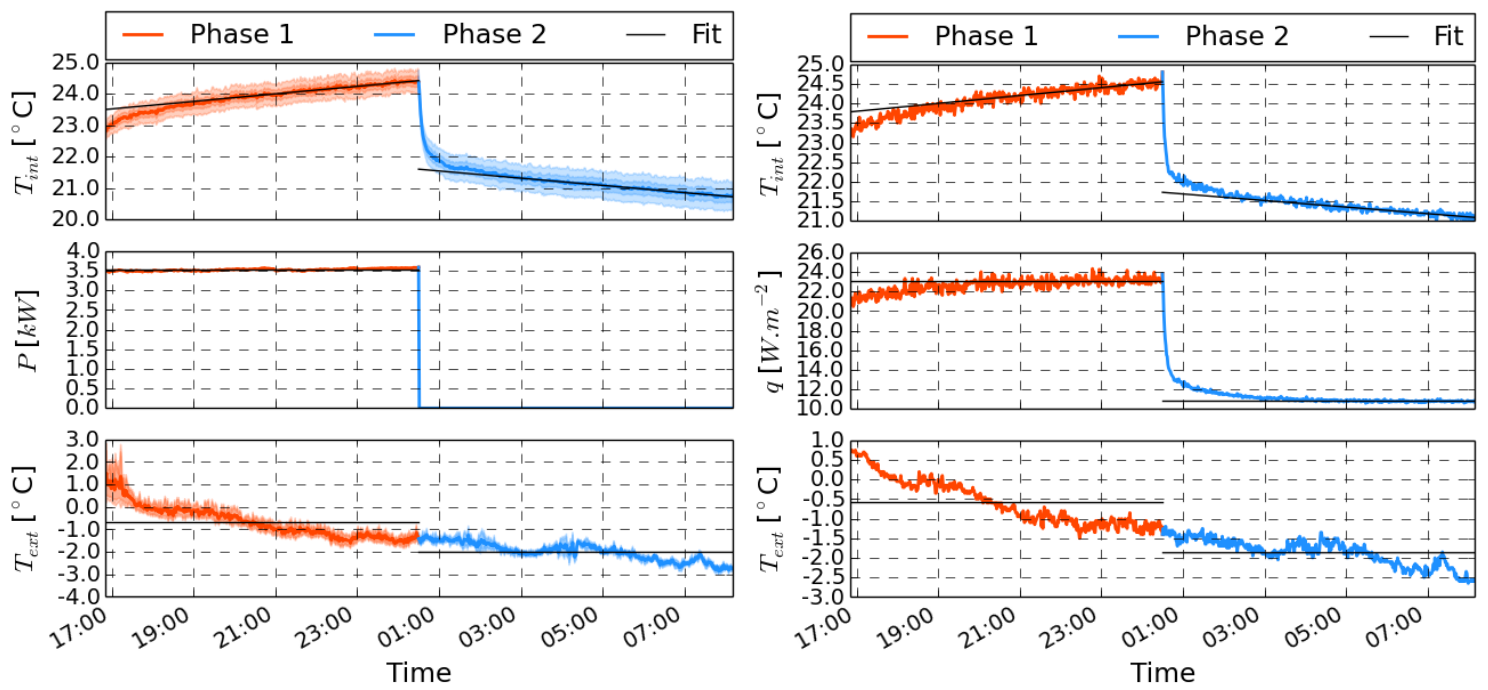

Figure 4: Evolution of air temperatures, heating power and heat flux density during a QUB/e test (test $\mathrm{n}^{\circ} 2$ ) in Årsta (Sweden) - Whole house heat loss coefficient (left) and in situ $U$-value of an external wall of bedroom 1 (right). The red, blue and black solid lines correspond to the heating phase, the free cooling phase and the linear regressions used to derive the quantities used in the QUB/e formula, respectively.

The whole HLC and the local $U$-values of a building can thus be estimated in one night using the QUB/e method. For more details on the QUB/e method and previous work, the interested reader should refer to $[5-9,15-17]$ and references therein.

\subsection{Monitoring equipment and testing protocol}

The tests were carried out when the apartment was unoccupied between December 13, 2016 and December 31, 2016. Three consecutive QUB/e tests were first undertaken at night followed by quasi steady-state measurements (ISO 9869-1) during 15 days. The mechanical ventilation was switched off. The heating system of the apartment was switched off only during the QUB/e tests. Electrical heaters (i.e., fan heaters) were placed within the apartment in order to provide a uniform heating source for the QUB/e tests. The total duration of each QUB/e test was 16 hours (i.e., between $4 \mathrm{pm}$ and 8am).

Heat flux plates (Hukseflux HFP01) and type K thermocouples were used to monitor the heat flux densities on building elements and the air temperatures. A silicone paste was used to ensure a good thermal contact between the heat flux plates and the building elements. All sensors were connected to data loggers (Graphtec GL820). Weather conditions (i.e., temperature, relative humidity, wind orientation and speed, solar radiation) were recorded with a Davis Vantage Pro2 weather station installed on the balcony of the apartment. The data acquisition rate was set to one minute.

In situ $U$-value measurements were also undertaken in accordance with ISO 9869-1 [10] (average method) while the set point temperature of the apartment was approximately $21^{\circ} \mathrm{C}$ (see Figure 2). In situ measurements of heat flux density, from which in situ $U$-values are derived, were taken at 25 locations on the thermal elements ( 7 on the external walls, 6 on the internal walls, 4 on the floor, 4 on the ceiling and 4 on the glazings) of the apartment using heat flux plates (HFPs). Only measurements of heat flux density obtained from those locations that were considered not to be significantly influenced by thermal bridging at junctions with neighbouring thermal elements (typically at distances greater than $500 \mathrm{~mm}$ 
from the junction) were used in the calculation of the in situ $U$-values. HFPs were also placed at the centre pane of the windows, i.e. only the $U_{g}$-value of these glazing units could be derived from our measurements. The $U$-values estimated in situ with the quasi-steady state (ISO 9869-1) and the QUB/e methods were compared.

Unfortunately, the whole HLC could not be estimated during this measurement period because the energy consumption of the apartment could not be monitored, i.e. only the overall energy consumption of the building was available.

The indoor air temperature was not kept constant during the QUB/e test so that there might have been a temperature difference across the internal walls, the floor and the ceiling separating the exhibition apartment and the neighbouring internal zones (apartments, corridor). Since the heat fluxes were monitored during the QUB/e tests, these internal heat losses (or gains) could be accounted for. The HLCs were thus corrected in order to report only heat losses (or gains) to the exterior environment and have a sound comparison with theoretical calculations which assume a uniform temperature within a building (i.e., there are no heat losses/gains).

The HLC with respect to the exterior environment was computed with the following equation:

$$
H L C_{e x t}=H L C_{\text {raw }}-\sum_{j} U_{e f f, j} \times A_{j}
$$

where $H L C_{\text {ext }}, H L C_{\text {raw }}, U_{e f f, j}$ and $A_{j}$ are the HLC w.r.t. the exterior environment only (in $\mathrm{W} \mathrm{K}^{-1}$ ), the 'raw' HLC (in $\mathrm{W} \mathrm{K}^{-1}$ ) obtained from the standard QUB analysis, the effective $U$-value of the $\mathrm{j}^{\text {th }}$ internal element (in $\mathrm{W} \mathrm{m}^{-2} \mathrm{~K}^{-1}$ ) obtained from the QUB/e method and the area of the $\mathrm{j}^{\text {th }}$ internal element (in $\mathrm{m}^{2}$ ), respectively.

\section{Results and discussion}

\subsection{Whole Heat Loss Coefficient (HLC)}

Figure 5 shows the whole heat loss coefficient (HLC) estimated with the QUB/e method for three consecutive nights. The internal heat losses (or gains) through the ceiling, the floor and the internal walls were accounted for with the estimation of the effective $U$-values. The experimental tests covered values of the parameter $\alpha$ between 0.4 and 0.7 (the value of the mean HLC was used as the reference HLC). The estimated values of the whole HLC with QUB/e method are thus deemed reliable. The QUB/e method yielded a robust estimation of the whole HLC with an estimated mean value of $47.4 \pm 2.6 \mathrm{~W} \mathrm{~K}^{-1}$. This value can be used to estimate the space heating needs of the apartment (e.g., with degree-days [19]).

The main source of uncertainty arose from the correction of the internal heat losses (or gains) derived from the estimated effective $U$-values. The effective $U$-values of the floor and the internal walls (neighbours, corridor) were almost nil while the effective $U$-value of the ceiling was quite high (i.e., around $0.27 \pm 0.12 \mathrm{~W} \mathrm{~m}^{-2} \mathrm{~K}^{-1}$ ). It was attributed to a much lower internal air temperature set point chosen by the upstairs neighbour(s). Unfortunately, we could not access the apartment to verify this assumption.

\subsection{Local $U$-values}

The $U$-values estimated with the quasi-steady state (ISO 9869-1) and the QUB/e methods are plotted against each other in Figure 6. Each symbol corresponds to the $U$-value of each HFP placed on the external walls (7 different locations) and the glazings (4 different locations). 


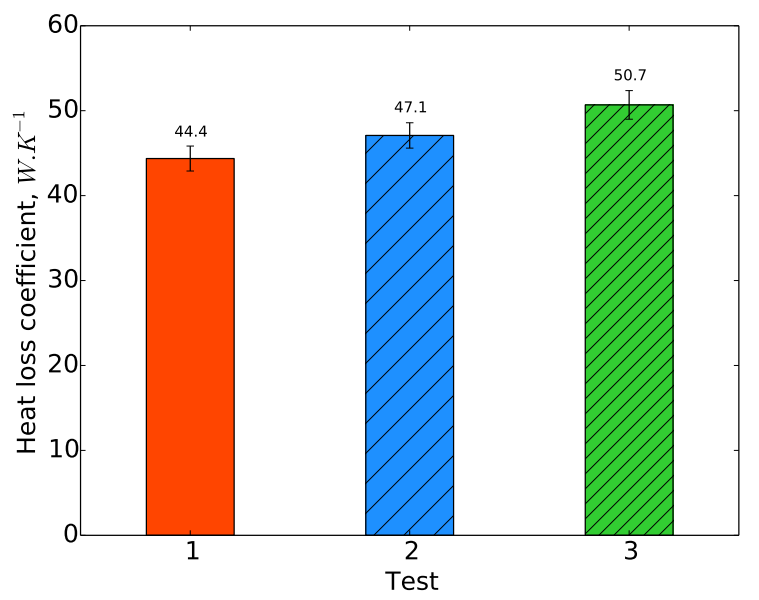

Figure 5: Whole heat loss coefficient (HLC)
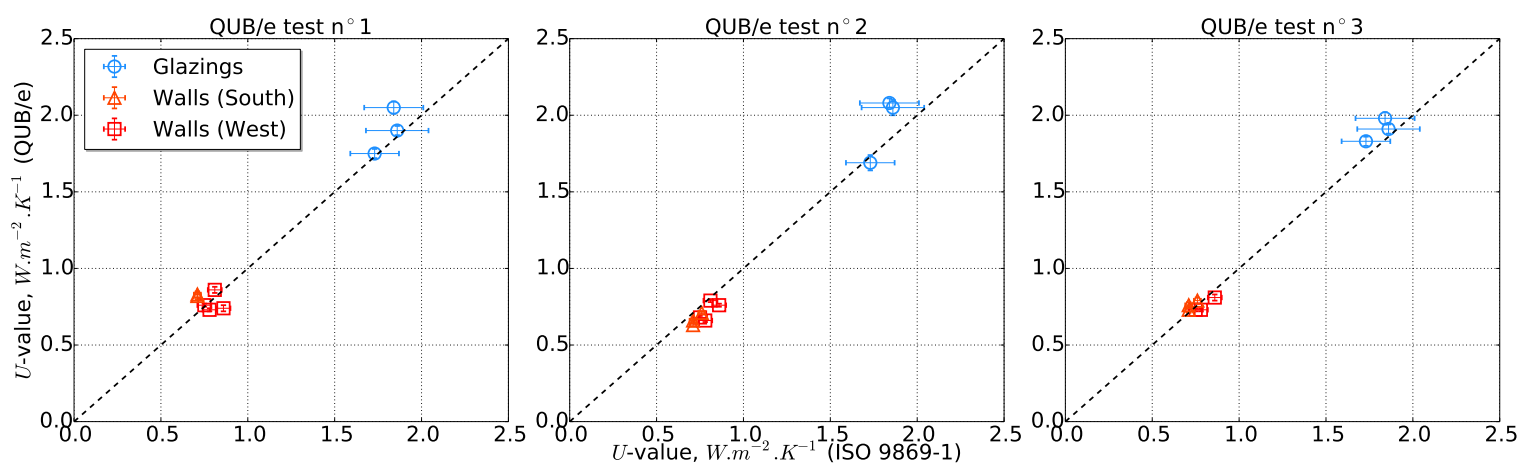

Figure 6: Local $U$-values: cross-comparison between ISO 9869-1 and QUB/e methods. For comparison, the $y=x$ reference curve is plotted for each case (dashed black lines).

The in situ measurements showed a good agreement between the quasi-steady state (ISO 9869-1) and the QUB/e methods (i.e., the relative differences were within the uncertainty bound of the measurement methods). It should be noted that the $U$-values measurements undertaken in accordance with ISO 9869-1 were obtained after a period of 15 days whereas each QUB/e test was performed in a single night. It was thus demonstrated that the QUB/e method can deliver a good estimation of the thermal performance of the building fabric in a single night without occupancy for this type of building.

The external walls seemed fairly homogenous thermally-wise with an estimated mean $U$-value of $0.77 \pm 0.05 \mathrm{~W} \mathrm{~m}^{-2} \mathrm{~K}^{-1}$ with the QUB/e method. This statement was backedup with a thermographic survey undertaken in accordance with EN 13187:1999 [11] (not reported here for the sake of brevity). The mean $U_{g^{-}}$value of the double glazing units (DGU) was estimated at $1.93 \pm 0.12 \mathrm{~W} \mathrm{~m}^{-2} \mathrm{~K}^{-1}$ with the QUB/e method. The slight discrepancy observed between the estimates based on the QUB/e and ISO 9869-1 tests (i.e., around 6\%) should be further investigated.

\section{Conclusions}

The findings from a series of in situ tests in a circa 1960s multi-family housing (MFH) carried to assess its thermal performance were presented in this work. The objectives of the study were to (i) evaluate the thermal performance of the building fabric (i.e., whole heat loss coefficient and local $U$-values) before a full retrofit programme, and (ii) validate the QUB/e 
method by cross-comparison with quasi steady-state measurements.

The in situ measurements showed a good agreement between the quasi-steady state (ISO 9869-1) and the QUB/e methods (i.e., the relative differences were within the uncertainty bound of the measurement methods). It was thus demonstrated that the QUB/e method can deliver a good estimation of the thermal performance of building fabrics within just one night without occupancy, significantly less than the 2-4 week period required for quasi steady-state methods. Although further comparison with quasi steady-state methods in real climates for different types of buildings is needed, the QUB/e method is a promising method to test the actual performance of buildings.

Acknowledgements: The author would like to thank Mika Hakosalo, Jan-Ulric Sjögren (Stockholms stad) and Harry Matero (Stockholmshem) for allowing us to perform these measurements in Årsta. The help of colleagues at Saint-Gobain (Tomas Pühringer, Theo Kiriakou, Andrea Mazzucco and Jean-Benoît Racaud) is also greatly appreciated.

\section{References}

[1] A. Stafford, M. Bell, and C. Gorse. Building Confidence - A working paper. Report 008, The Centre for Low Carbon Futures, March 2012.

[2] Zero Carbon Hub. Closing the Gap Between Design and As-built Performance - Evidence Review Report. Technical report, London, UK, March 2014.

[3] D. Johnston, D. Miles-Shenton, and D. Farmer. Quantifying the domestic building fabric a 'performance gap'. Building Services Engineering Research and Technology, $36(5): 614-27,2015$.

[4] A. Janssens. International Energy Agency, EBC Annex 58 - Reliable building energy performance characterisation based on full scale dynamic measurements. Report of Subtask 1b: Overview of methods to analyse dynamic data. Technical report, KU Leuven, Leuven (Belgium), 2016.

[5] J. Meulemans, F. Alzetto, D. Farmer, and C. Gorse. QUB/e - A novel transient experimental method for in situ measurements of the thermal performance of building fabrics. In C. Gorse and M. Dastbaz, editors, International SEEDS Conference 2016: Sustainable Ecological Engineering Design for Society, Leeds, UK, 14-15 September 2016 .

[6] J. Meulemans, F. Alzetto, D. Farmer, and C. Gorse. Building Information Modelling, Building Performance, Design and Smart Construction, chapter QUB/e - A Novel Transient Experimental Method for in situ Measurements of the Thermal Performance of Building Fabrics. Springer International Publishing AG, $1^{\text {st }}$ edition, April 2017.

[7] G. Pandraud, E. Mangematin, D. Roux, and E. Quentin. QUB: a new rapid building energy diagnosis method. In Proceedings of CLIMA 2013. The $11^{\text {th }}$ REHVA World Congress and the $8^{\text {th }}$ International Conference on IAQVEC, Prague (Czech Republic), June 13-19 2013.

[8] F. Alzetto, G. Pandraud, and R. Fitton. The QUB Method: a Fast and Reliable Building Envelope Thermal Diagnosis. Preprint submitted to Energy and Buildings, 2016.

[9] V. Sougkakis, J. Meulemans, F. Alzetto, C. Wood, M. Gillott, and T. Cox. An assessment of the QUB method for predicting the whole building thermal performance 
under actual operating conditions. In C. Gorse and M. Dastbaz, editors, International SEEDS Conference 2017: Sustainable Ecological Engineering Design for Society, Leeds, UK, 13-14 September 2017.

[10] ISO 9869-1:2014. Thermal insulation - Building elements - In-situ measurement of thermal resistance and thermal transmittance - Part 1: Heat flow meter method, 2014.

[11] BS EN 13187:1999. Thermal performance of buildings - Qualitative detection of thermal irregularities in building envelopes - Infrared method.

[12] D. Johnston, D. Miles-Shenton, D. Farmer, and J. Wingfield. Whole House Heat Loss Test Method (Coheating). Technical report, Leeds Metropolitan University, 2013.

[13] G. Bauwens and S. Roels. Co-heating test: A state-of-the-art. Energy and Buildings, 82(0):163-72, 2014.

[14] A. Stafford, D. Johnston, D. Miles-Shenton, D. Farmer, M. Brooke-Peat, and C. Gorse. Adding value and meaning to coheating tests. Structural Survey, 32(4):331-42, 2014.

[15] E. Mangematin, G. Pandraud, and D. Roux. Quick measurements of energy efficiency of buildings. Comptes Rendus Physique, 13(4):383-90, 2012.

[16] G. Pandraud and R. Fitton. QUB: Validation of a Rapid Energy Diagnosis Method for Buildings. In IEA-EBC Annex 58, $4^{\text {th }}$ Expert meeting, Holzkirchen (Germany), April 8-10 2013.

[17] G. Pandraud, D. Gossard, and F. Alzetto. Experimental optimization of the QUB method. In IEA-EBC Annex 58, $6^{\text {th }}$ Expert meeting, Ghent (Belgium), April 14-16 2014 .

[18] H.W. Coleman and W.G. Steele. Experimentation, Validation, and Uncertainty Analysis for Engineers. John Wiley \& Sons, Inc., Hoboken, New Jersey, 2009.

[19] T. Day. Degree-days: theory and application. Technical Report TM41: 2006, Chartered Institution of Building Services Engineers (CIBSE), 2006. 